\title{
Grain-size distribution of volcaniclastic rocks 1: A new technique based on functional stereology
}

\author{
M. Jutzeler ${ }^{\mathrm{a}, *}$, A.A. Proussevitch ${ }^{\text {b }}$, S.R. Allen ${ }^{\text {a }}$ \\ a CODES - Centre of Excellence in Ore Deposits, University of Tasmania, Private bag 79, Hobart, TAS 7001, Australia \\ b Earth Systems Research Center, Institute for the Study of Earth, Oceans, and Space, University of New Hampshire, Durham, NH 03824, USA
}

\section{A R T I C L E I N F O}

Article history:

Received 11 September 2011

Accepted 16 May 2012

Available online 1 June 2012

\section{Keywords:}

Grain size distribution

Grain size analysis

Functional stereology

Volcaniclastic rock

Pyroclastic rock

Welded ignimbrite

Clastic rock

\begin{abstract}
A B S T R A C T
The power of explosive volcanic eruptions is reflected in the grain size distribution and dispersal of their pyroclastic deposits. Grain size also forms part of lithofacies characteristics that are necessary to determine transport and depositional mechanisms responsible for producing pyroclastic deposits. However, the common process of welding and rock lithification prevents quantification of grain size by traditional sieving methods for deposits in the rock record. Here we show that functional stereology can be used to obtain actual 3D volume fractions of clast populations from 2D cross-sectional images. Tests made on artificially consolidated rocks demonstrate successful correlations with traditional sieving method. We show that the true grain size distribution is finer grained than its representation on a random 2D section. Our method allows the original size of vesicular pumice clasts to be estimated from their compacted shapes. We anticipate that the original grain-size distribution of welded ignimbrites can also be characterized by this method. Our method using functional stereology can be universally applied to any type of consolidated, weakly to non-deformed clastic material, regardless of grain size or age and therefore has a wide application in geology.
\end{abstract}

(c) 2012 Elsevier B.V. All rights reserved.

\section{Introduction}

The grain size distribution of pyroclastic deposits reflects processes of fragmentation, transport and deposition (Walker, 1971, 1973; Wohletz et al., 1989), and is a fundamental input to inverse physical models of explosive eruptions (e.g. Bonadonna and Houghton, 2005; Dufek and Bergantz, 2007; Macedonio et al., 2008; Volentik et al., 2010). Presently, grain size distributions of pyroclastic deposits are obtained by sieving coarse fractions ( $>64 \mu \mathrm{m})$, and by laser diffraction and optical devices for finer ash (e.g. Evans et al., 2009). These methods are exclusively used for loose, unconsolidated deposits, and the grain (or clast) population is represented as a function of the intermediate feret diameter of each particle and its weight. Consequently, most physical models of explosive volcanic eruptions are on modern deposits and are almost exclusively based on subaerial examples, because available data are limited to unwelded and unconsolidated aggregates. The grain size distributions of the largest part of the accessible volcaniclastic deposits on Earth - the rock record - have not been quantitatively studied, as clastic rocks cannot be sieved. The same basic problem occurs in traditional detrital sedimentology (Boggs, 2006), so solutions found for pyroclastic deposits can be applied to other volcaniclastic and non-volcanic clastic deposits as well.

\footnotetext{
* Corresponding author at: Department of Geology, University of Otago, PO Box 56, 9054 Dunedin, New Zealand. Tel.: + 64211550799 (mobile).

E-mail address: jutzeler@gmail.com (M. Jutzeler).
}

Pyroclastic deposits incorporate a wide range of grain sizes (extrema from $10^{1}$ to $<10^{-6} \mathrm{~m}$ ). They can form and be deposited in both subaerial and subaqueous environments (Cas and Wright, 1987; McPhie et al., 1993; Schmincke, 2004), and be transported by various drag agents (high-temperature volcanic gas, air, water, ice and mixtures). Pyroclasts are commonly entirely composed of volcanic glass, phenocrysts, and vesicles from exsolved fluids.

The lithification of pyroclastic deposits is accomplished by welding of hot juvenile pyroclasts, and/or by diagenetic or hydrothermal alteration. Most pyroclastic deposits have undergone unidirectional compaction during welding and/or diagenesis (Quane and Russell, 2005). The inherent porosity of pumice and scoria clasts makes them very susceptible to flattening prior to or during lithification. Lithification may be accompanied by an irreversible obliteration of part or all of the original fine-grained particles, the minimum preserved grain size being commonly around $0.5-2 \mathrm{~mm}$. Therefore, only the coarsegrained fraction $(>2 \mathrm{~mm}$ ) of clastic rocks is considered in this study.

Here, we describe a new method to statistically calculate the threedimensional grain size distribution of clastic rocks. This method involves two steps (1) image analysis, which is the processing of photographs taken in the field or scans of samples to select and calculate the particle characteristics (feret diameters, aspect ratio) of clasts of the same type; and (2) functional stereology which is the conversion of twodimensional (2D) diameters of a population of the same clasts into a three-dimensional (3D) dataset, using deconvolution of pre-defined distribution functions. This method uses the functional stereology 
technique that is built on earlier formulations of discrete stereology and a study of continuous distribution functions in application to volcanology (Sahagian and Proussevitch, 1998; Proussevitch et al., 2007a, 2007b). This method allows the assessment of the grain size distribution density quantitatively which, in turn, can be converted to volume per phi and weight percent functions of particle size. The application of the method to subaqueous and subaerial volcaniclastic facies is the subject of a companion paper. Detailed formulations and a user-friendly software interface to functional stereology methods are under elaboration, and will be presented in a separate publication elsewhere. Here, only two main clast types are considered: (1) pumice clasts, which are 60-90\% vesicular and are intermediate to silicic in composition; and (2) dense clasts, which comprise all non-vesicular clasts.

\section{Image analysis}

Digital image processing of clastic textures is a powerful tool for quantification of clast properties (e.g. Capaccioni et al., 1997; Karatson et al., 2002). Image analysis can be used from any medium, including field photographs or scans of rock slabs and thin sections (Fig. 1). The original images must be taken at orthogonal angles to the studied surface, or artificially corrected with specialized software. The images must be scaled with a known object length (ruler, hammer, person, etc.), or by predefined scanning resolution or microscope magnification. In contrast to most grain size acquisition methods, the functional stereology technique does not depend on the scale of the sample. This implies that input images for image analysis can range over several orders of magnitude (tens of meters to millimeters). We have used image nesting strategy similar to that used in vesicularity studies (Shea et al., 2010) because the entire clast size range could not be described from a single image due to pixel resolution limitations (Fig. 1).

Use of automated recognition software (e.g. Proussevitch and Sahagian, 2001; Van Den Berg et al., 2002) is a rapid technique, but accurate only for images that contain distinct object contrast and boundaries that allow computer guided image segmentation (Gonzalez and Woods, 2008). In most of our natural samples, clast-clast contacts and additional "noise" within the clasts and the fine-grained matrix (including variations in color, slight compaction and presence of secondary crystals) precluded an automated procedure. Single clasts were "manually" outlined in every image, using the multiple selection tools of Adobe Photoshop software (Fig. 1). The time needed for manual image acquisition depends on the complexity of the rock, but commonly require $<0.5-4 \mathrm{~h}$ per image for an experienced user. For ideal samples in which clasts are not touching each other, use of an automated method considerably reduces this time to a couple of minutes. Once clasts were outlined, discrete clast parameters were acquired with image analysis software AnalySIS, including area, perimeter, various types of maximum and intermediate diameters, aspect ratio, shape factor and angle of the long-axis relative to a defined line, commonly perpendicular to the main axis of compaction.

Few errors are associated with this method and can reasonably be minimized, including the representativeness of the sample, the randomness of clast orientation, the orthogonal projection of the image, the clarity of grain boundaries, estimation of the density of each type of clast, and the approximation of the grain shapes to a common geometry (Sahagian and Proussevitch, 1998). The shapes of volcanic clasts are much less complex than highly tortuous shapes of vesicles in pumice clasts (e.g. Shea et al., 2010), and are simplified to oblate rotational ellipsoids (Sahagian and Proussevitch, 1998). The functional stereology technique requires statistically representative populations of at least a couple of hundred grains in order to reduce random scatter to a reasonable level. Generally, one outcrop photo and one rock slab scan gave good precision for functional stereology, and were sufficient to obtain a representative clast population, as well as acceptable data overlap. The precision of the stereology technique for the coarsest and finest tails of the distribution may be low. Clasts abnormally big in size on a $2 \mathrm{D}$ section cannot be statistically reproduced in $3 \mathrm{D}$ if their abundance is too low. Furthermore, the grain size study of clastic rocks is limited by the state of texture preservation. The cut-off grain size that can be analyzed depends on the rock but is commonly $2 \mathrm{~mm}$. The systematic use of high-definition digital photos ( $>6 * 10^{6}$ pixels) and scans (1200 ppi) prevented pixelation for clasts in this size, thus the clast shapes and diameters were sufficiently accurate. In addition, the image should only be taken from a reasonably even rock surface. For the conversion of volume to weight of particles, the density of each type of clast is needed. This remains difficult to evaluate without study of the density and vesicularity of each grain (e.g. heterogeneously vesicular pumice clasts can be less dense than others by a factor of $\sim 2$ ).

\section{The stereology technique}

The clast dimensions found on a 2D section do not statistically represent true three-dimensional clast diameters. Stereology is the reconstruction of 3D objects from 2D imagery, and has been the subject of numerous contributions concerned with crystal populations in igneous rocks (e.g. Cashman, 1988; Sahagian and Proussevitch, 1998; Higgins, 2000; Castro et al., 2003; Mock and Jerram, 2005; Jerram and Davidson, 2007) and bubbles in magma (Sahagian and Proussevitch, 1998; Proussevitch et al., 2007a, 2007b; Shea et al., 2010). Stereology is an efficient alternative to sieving in grain size studies and to 3D imaging by X-ray tomography (e.g. Gualda and Rivers, 2006; Degruyter et al., 2010; Gualda et al., 2010; Jerram et al., 2010; Kervyn et al., 2010; Ketcham et al., 2010).

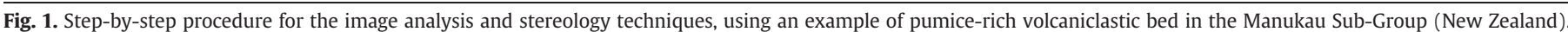

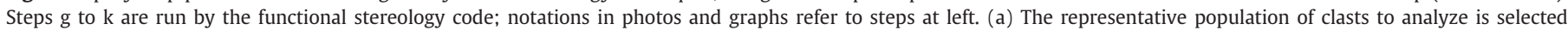

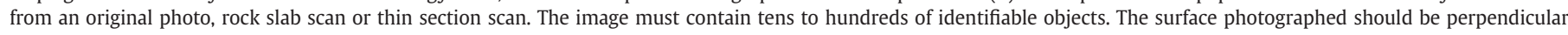

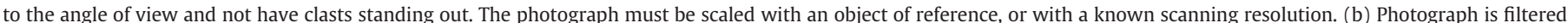

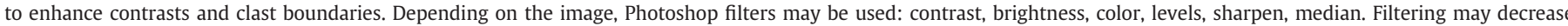

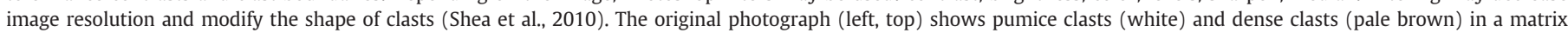

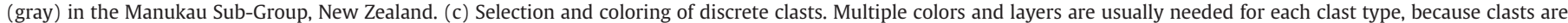

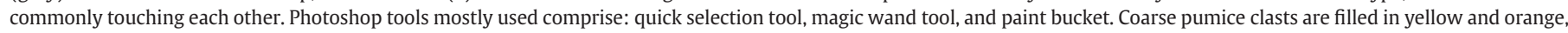

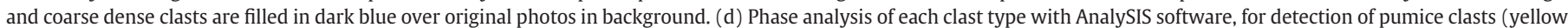

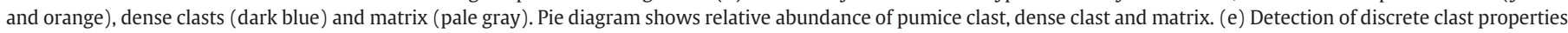

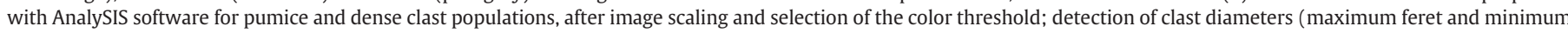

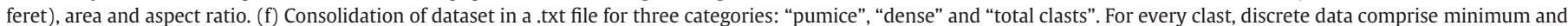

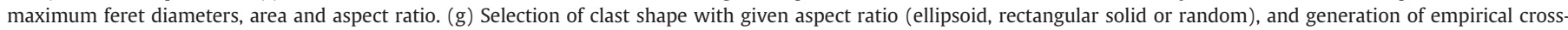

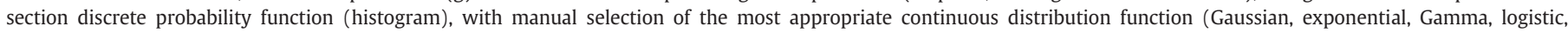

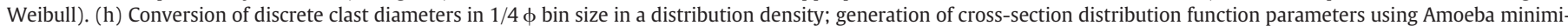

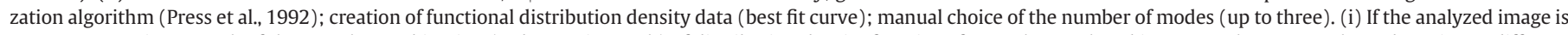

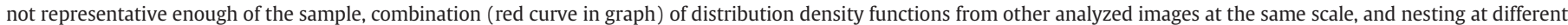

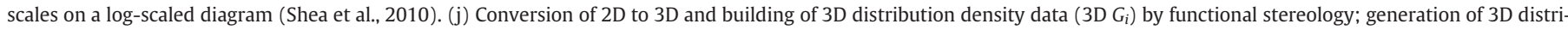

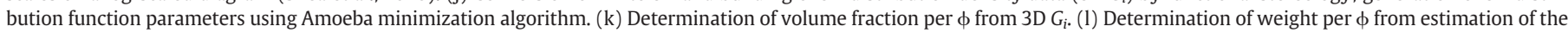
density of each clast type (density = mass/volume). (m) Determination of total weight per $\phi$ by addition of the separate weight of all types of clast. 
The concept of stereology lies in the difference in apparent grain diameter on a 2D section compared to the real 3D grain size population (Kellerhals et al., 1975; Sahagian and Proussevitch, 1998; Proussevitch et al., 2007b). For instance, cross-section size almost never represents the true size, as a random 2D section rarely crosses through a grain center. This means $2 \mathrm{D}$ sections are particularly poor for acquiring the maximum clast diameter in a population. Additional bias is introduced because small-diameter particles in a randomly distributed grain population have lower probability to appear in a random 2D section than coarser particles, thus causing a significant shift and overestimating towards a coarser apparent grain size distribution.

In order to correct for the misrepresentation of grain size distributions involved in the examination of cross sections, the embedded basic tools of functional stereology can be applied, thus deriving
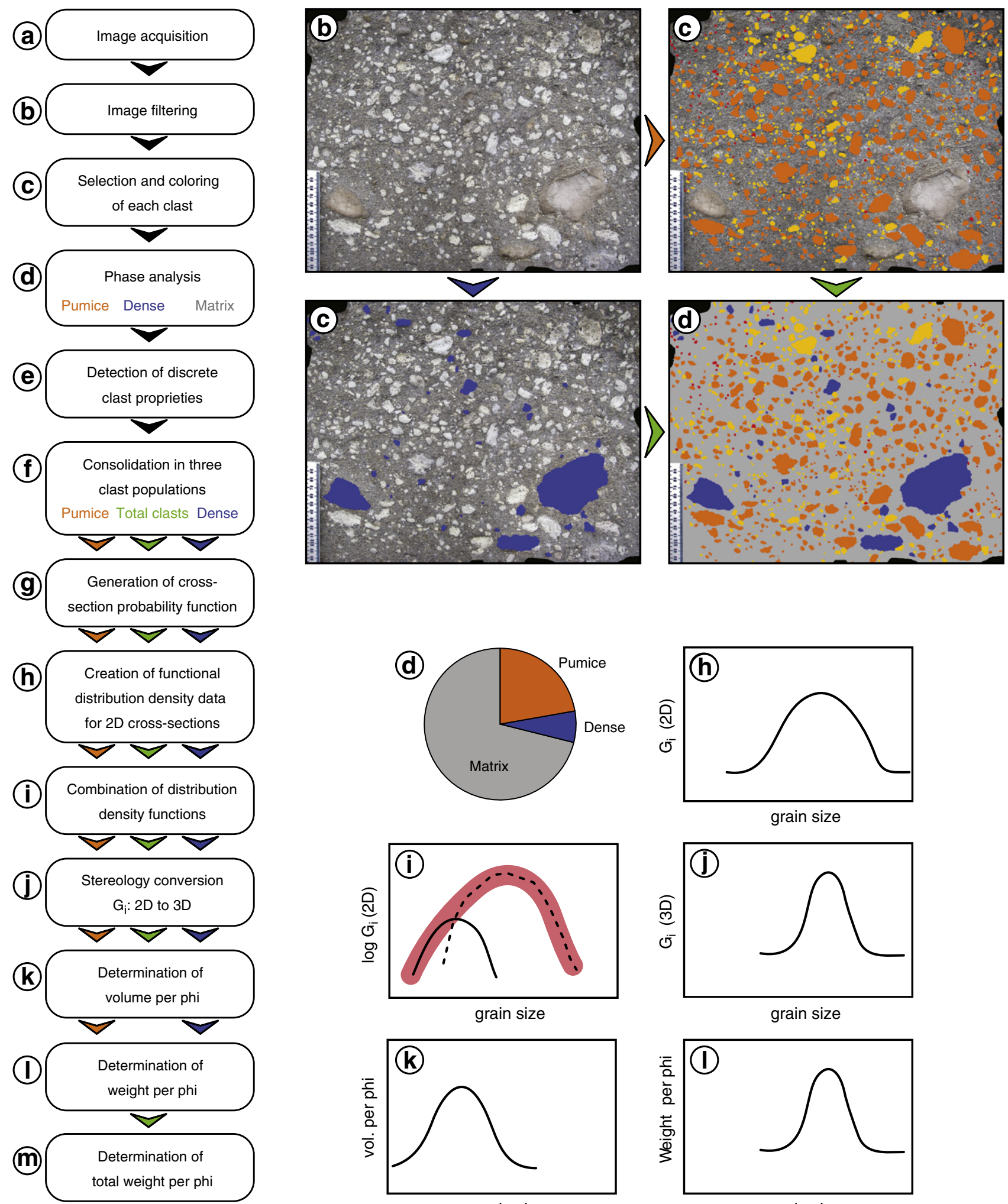

grain size
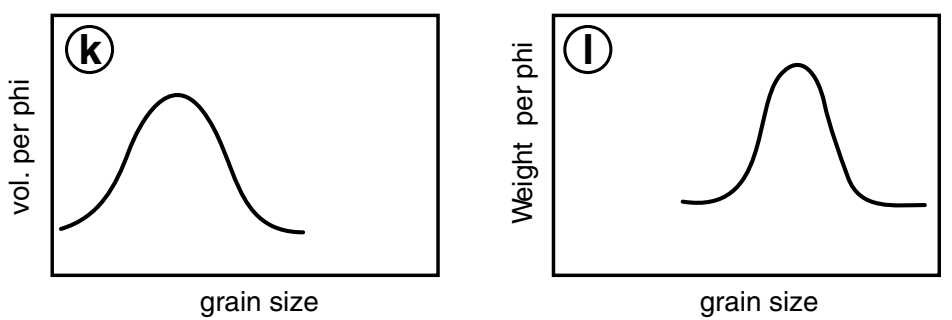
inferred 3D volume information from simple 2D observations. Here, the discrete stereology approach of Sahagian and Proussevitch (1998) was improved for developing a new method, the functional stereology that converts measurements of grain cross-sections by deconvolution of pre-defined functions of their 3D sizes (Fig. 1). The user can choose a continuous distribution function to perform 2D-3D conversion that best fits observed 2D grain size histograms. A choice of the various log-scaled functions (normal/Gaussian, exponential, Gamma, logistic, Weibull) is available in the embedded functional stereology code. The samples studied in this paper best match a log-normal behavior, as does a large selection of natural object sizing categories (Proussevitch et al., 2007a, 2007b). The output of the stereology method gives values of $G_{i}$, which represent the grain number distribution density, and equal the number of particles per $\mathrm{m}^{2}$ or $\mathrm{m}^{3}$ and per bin width, in $\left(\mathrm{m}^{2} \phi\right)^{-1}$ or $\left(\mathrm{m}^{3} \phi\right)^{-1}$, respectively (Fig. 2). As such, stereology is an inexpensive, rapid and straightforward technique, which only necessitates discrete clast dimensions extracted by image analysis and a special routine for functional stereology described below.

\subsection{Formulation of the functional stereology technique}

The discrete distribution $G_{i}$ is defined by continuous number density distribution function $n(V)$. It can be defined with the following relation in a general form for 2D and 3D cases (Proussevitch et al., 2007b):

$n(V)=\sum_{j} N_{j}^{\text {total }} \hat{f}_{j}(V)$

where $N_{j}^{\text {total }}$ and $\hat{f}_{j}(V)$ are cumulative number density and unitless probability density function for mode $j$ commonly referred to as PDF (Bruning and Kintz, 1997).

Considering that the relation between 2D and 3D grain size distribution can be expressed by:

$g(x) d x=\hat{H} \iint_{x}^{+\infty} \gamma\left(\frac{x}{z}\right) z f(z) d\left(\frac{x}{z}\right) d z$

where $g(x)$ and $f(x)$ are $G_{i}$ in 2D and 3D respectively, $x$ is a linear dimension for grain size, $\gamma(\bar{x})$ is a dimensionless function for a distribution density function of cross-section of relative size $\bar{x}$, defined (Sahagian and Proussevitch, 1998) as $\bar{x}=x / x_{\max }$, and $\hat{H}$ is dimensionless mean projected height coefficient, defined as ratio of particle mean projected area to its size $\hat{H}=\bar{H} / D$.

From Eq. (1), the stereological conversion of an arbitrary distribution function for a 2D cross-section $g(x)$ can be performed by solving
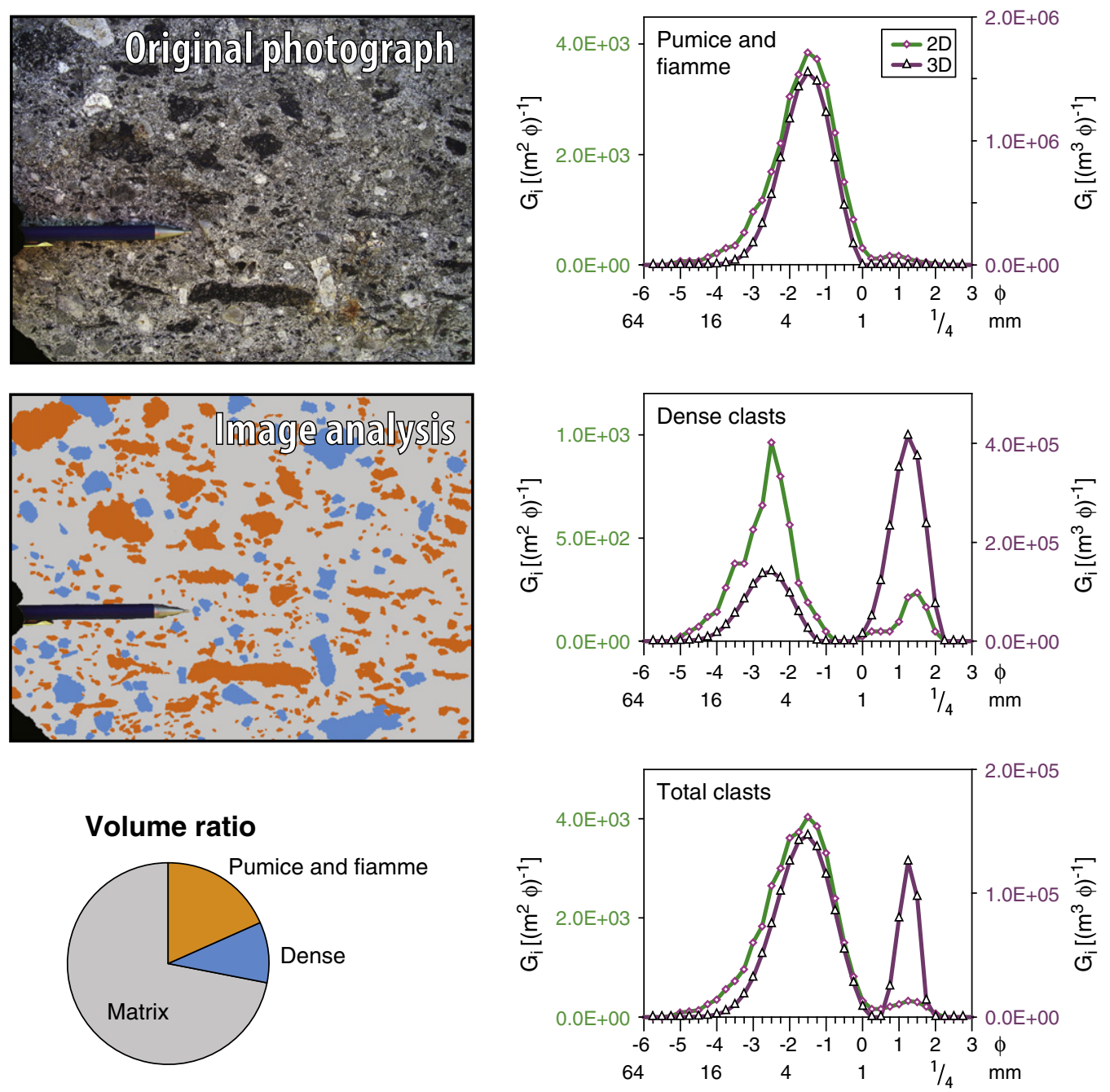

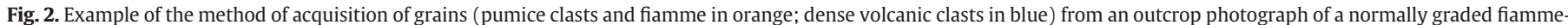

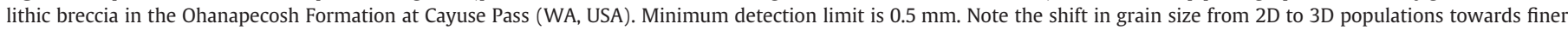

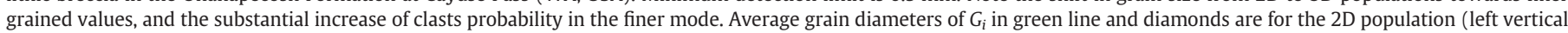
scale), purple line and triangles are for calculated 3D population (right vertical scale). Bin interval is $1 / 4 \phi$. Visible part of the pencil is $10.0 \mathrm{~cm}$ long. 
the first type of the Fredholm form integral equation (Polyanin and Manzhirov, 2008), in regard of function $f(x)$ :

$g(x)=\hat{H} \int_{x}^{+\infty} \frac{x}{y} \gamma\left(\frac{x}{z}\right) f(z) d z$

\section{Validation of the method}

\subsection{Samples, sieving and synthetic rock preparation}

To compare functional stereology results with those from sieving, synthetic rocks were constructed by embedding clasts in epoxy cement (Fig. 3). This method complements the theoretical tests of the stereology technique undertaken on bubble populations (Proussevitch et al., 2007a). The samples consisted of $\sim 10 \mathrm{~cm}^{3}$ of various populations of clasts (Fig. 4) from industrial sites in Tasmania (Australia) and from various pumice-rich pyroclastic deposits in the Taupo Volcanic Zone (New Zealand).

First, the unconsolidated samples were sieved and weighed to generate conventional weight percent histograms of grain size (Fig. 4; e.g. Folk, 1980). The diverse samples were sieved at $1 \phi$ intervals on the range -5 to $1 \phi$ to simplify sieving and image analysis procedures on extreme grain sizes; the finer particles $(>1 \phi)$ were discarded. Each sample comprised clasts of assumed similar densities to allow the direct conversion of weight percent into volume fractions.

The sieved splits were then combined and placed in a vessel and gently shaken until clasts were randomly spread. Samples were immersed in colored epoxy and placed under $80 \mathrm{kPa}$ vacuum for an hour to remove porosity from the epoxy resin, then left to polymerize for several days. Once solid, the samples were sawn in to one or multiple parallel slabs, polished and digitized at 1200 dpi on a flat screen scanner. Spacing between adjacent slabs was wide enough to avoid clasts to be cross-cut twice and appear on multiple slabs. The slab grain-size distribution was acquired using the image analysis and functional stereology methods detailed earlier, to be compared with the sieving data (Figs. 3, and 4).

\subsection{Application from output of the functional stereology}

For simplicity, this study follows the logarithmic grain size scale to the base two $(\phi)$ commonly used for sieved samples, where $d$ is the clast diameter (Wentworth, 1922; Krumbein, 1936; Walker, 1971, 1973; Folk, 1980).

$\phi=\log _{2}(d)$
The typical aspect ratio ( $A=$ length/thickness) of pyroclasts in our samples is in the range of 1.5 to 2.5 . To fit the sieving technique which sorts clasts by intermediate feret diameter (Walton, 1948), the average grain diameter output $\phi_{\text {average }}$ is corrected by the aspect ratio factor $A$, so accounting for the fact that the shorter ellipsoid axis allows a particle to go through the sieving mesh of size $\phi_{\text {sieving: }}$

$\phi_{\text {sieving }}=\phi_{\text {average }}+\log _{2}\left(\frac{A+1}{2}\right)$

The conversion of a $G_{i}$ bin population into a bin volume fraction under a $\phi$ scale is approximated by:

$V_{i}^{g}=G_{i} \triangle \phi v_{i}^{g}$

where $V_{l}^{g}$ is volume of all grains in the bin $i$ of size $\phi_{\mathrm{i}}$ (in $\mathrm{m}^{3}$ ), $G_{i}$ is a grain number density in respect to $\phi$ in $\left(\mathrm{m}^{3} \phi\right)^{-1}, \Delta \phi$ is the bin interval and $\phi_{i}$ is a class size or average clast size in it. The product (multiplication) of $G_{i}$ and $\Delta \phi$ is actually the number of grains in the bin $i$, and so multiplying it by the average volume of a single grain in this bin $v_{i}^{g}$ makes the $V_{i}^{g}$ value. The volume of a single grain in the bin $i$ with average size $\phi_{i}$ follows from Eq. (4) where, for simplicity, we use approximation of particle shape as sphere (a prolate rotational ellipsoid approximation accounting for the aspect ratio $A$ could be somewhat more realistic, but its algebraic form is quite complicated and not present here):

$V_{i}^{g}=10^{-9} \cdot \frac{\pi}{6}\left(2^{-\phi_{\mathrm{i}}}\right)^{3}$

Conversion of volume $V\left[\mathrm{~m}^{3}\right]$ obtained in Eq. (6) into a weight of sieved fraction $W[\mathrm{~kg}]$ requires a known or assumed bulk density $(\rho)$ for each clast type in the sample:

$W=\rho V$

Eqs. (5) through (8) allow converting stereology derived $G_{i}$ data to sieving weight fraction and vice versa which are used for stereology validation given in the next section.

\subsection{Results of the tests of stereology vs. sieving}

The functional stereology technique consistently reproduced the form of the grain size distributions obtained from sieving, demonstrating the accuracy of the image analysis and functional stereology
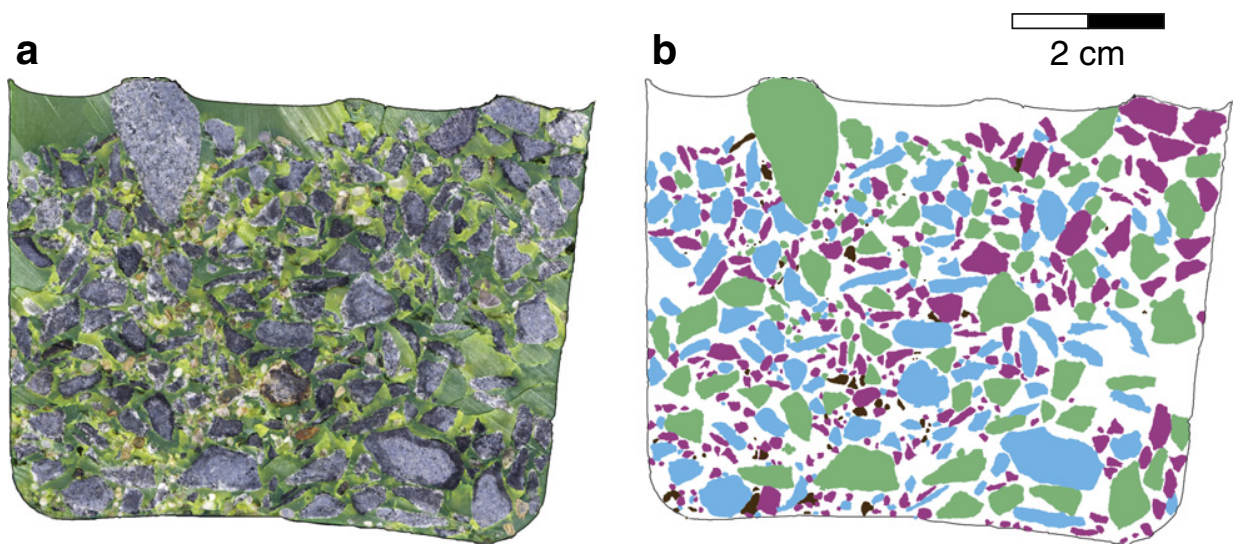

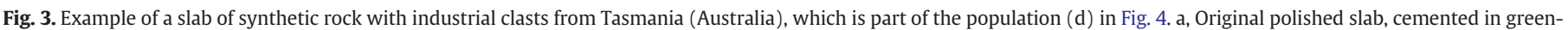
dyed epoxy. b, Image analysis of a single clast population, using numerous colors to separate touching clasts. 

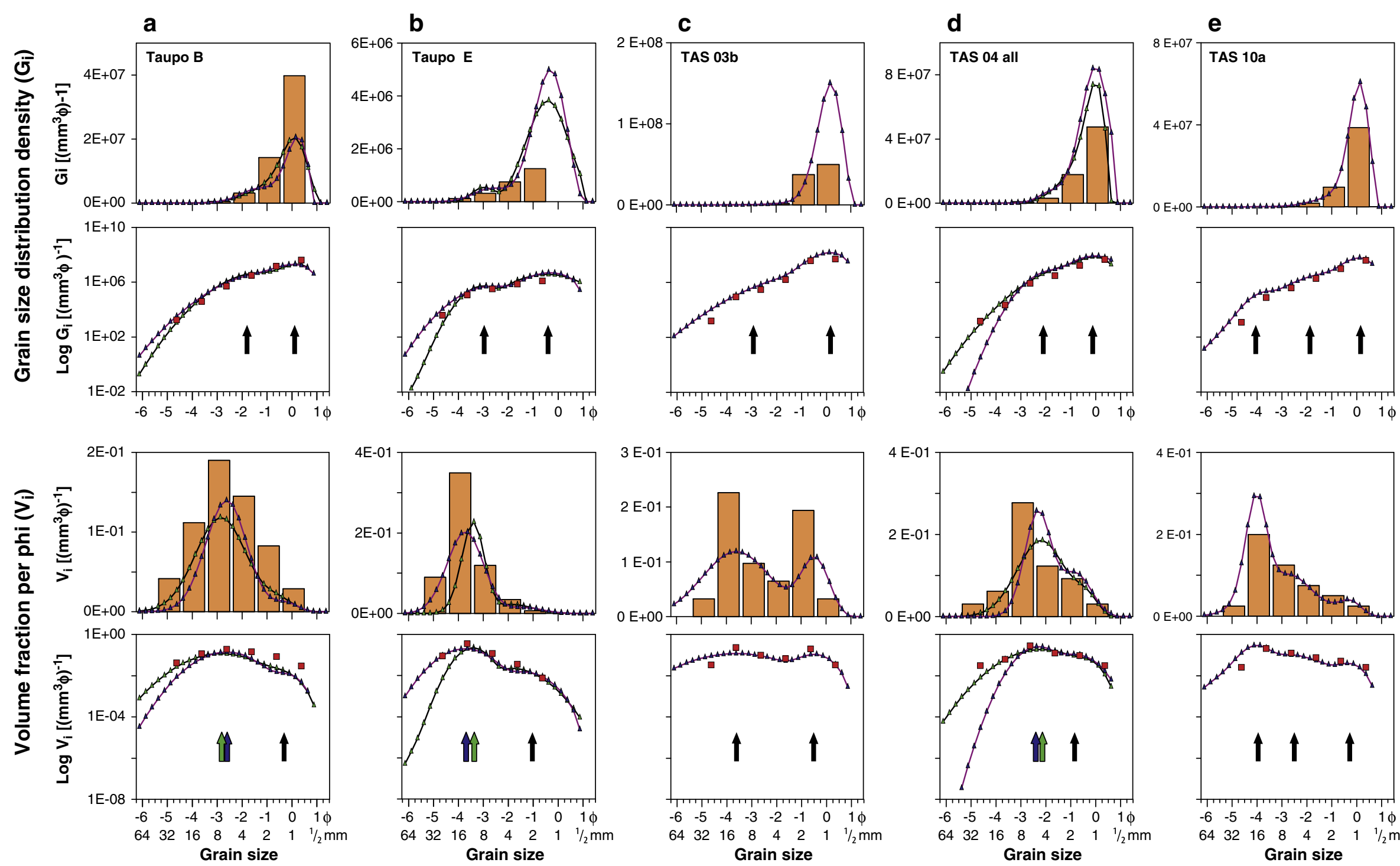

$\begin{array}{lllllllll}-6 & -5 & -4 & -3 & -2 & -1 & 0 & 1 \phi\end{array}$

$\begin{array}{llllllll}64 & 32 & 16 & 8 & 4 & 2 & 1 & 1 / 2 \mathrm{~mm}\end{array}$

Grain size

\section{$\rightarrow \rightarrow$ Functional stereology on artificial sample}

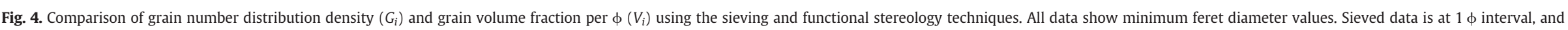

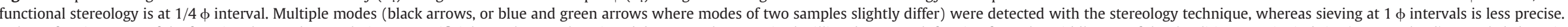

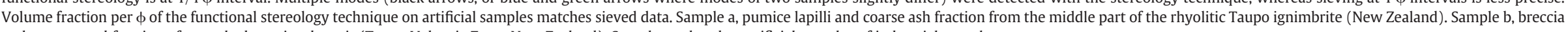
and coarse sand fraction of reworked pumice deposit (Taupo Volcanic Zone, New Zealand). Samples c, d and e, artificial samples of industrial gravels. 
methods (Fig. 4). The modes of the $G_{i}$ and volume per $\phi\left(V_{i}\right)$ are reproduced with accuracy.

In the functional stereology technique, the bin size at $1 / 4 \phi$ permits definition of the distribution curve with a better precision than for sieving at $1 \phi$, and various secondary modes are better defined than by sieving. As expected from Eqs. (6) and (7), there is a large quantity of fine-grained clasts ( $G_{i}$ spans -1 to $1 \phi$ ) but they comprise less volume in proportion to the coarser clasts ( $V_{i}$ spans -5 to $\left.-1 \phi\right)$, because volume scales to the cube of the clast radius (Fig. 4).

The use of a small bin size is critical for the study of poly-modal distributions. A relatively wide bin size ( $1 / 2$ to $1 \phi)$ has a high-pass filter effect on poly-modal distributions; secondary modes cannot be identified and the mode is not representative of the distribution (Fig. 5). Small bin sizes ( 0.1 to $1 / 4 \phi$ ) allow better identification of secondary modes and refine the value of the modes, although it may slightly increase the random noise. A major disturbance inherent from the calculation by functional stereology occurs (Fig. 3 in Sahagian and Proussevitch, 1998) where the bin size is too wide ( $1 / 2$ to $1 \phi)$. The $G_{i}$ is shifted towards fine grained values, and consequently the $V_{i}$ is shifted towards coarser grained values (Fig. 5). Thus, fine bin size $(<1 / 2 \phi)$ is more accurate using functional stereology for such clast populations where the distance between the adjacent modes is relatively small $(\sim 2 \phi)$.

A few stereology curves do not perfectly fit the sieving data (Fig. 4). These small shifts reflect the natural discrepancies in shape of a few clasts, or that the grain size distribution does not perfectly follow a log-normal behavior. The functional stereology code allows the user to decide, through choices of primary distribution functions, which one is most appropriate. Coarse grained products of fragmentation
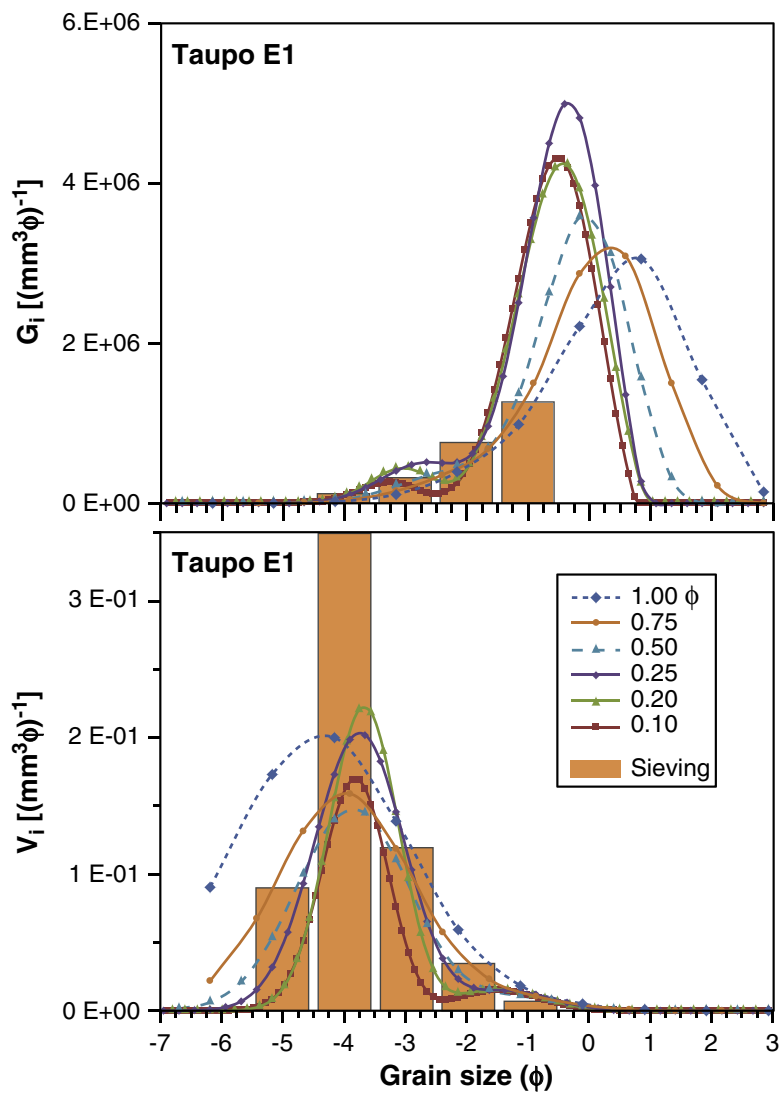

Fig. 5. Example of variations in $G_{i}$ and $V_{i}$ by varying the bin size, using the sample Taupo E1. The lateral shift in the distribution towards finer values for wide bins is related to the limits of the functional stereology at wide bins. Modes of $V_{i}$ are less affected than those of $G_{i}$. Note that the wide bins are monomodal, whereas small bins show two modes $(-3.75$ and $-1.4 \phi)$ in the lower graph. processes can be approximated by Gaussian (log-normal) distributions. Comparing results from different distribution functions show (Fig. 6) that log-normal, logistic and Gamma distributions give similar results. The Weibull distribution does not reproduce the shape of our samples. In this paper, we consistently used the log-normal distribution over other distributions, because it effectively reproduces clast distribution by fragmentation, and it is widely used and interpreted in material sciences. The Gamma distribution accounts for asymmetry, and it still results in a similar match as the log-normal, however its generic parameters cannot be interpreted by actual physical processes. The logistic is similar to the log-normal distribution, but its stronger kurtosis increases the importance of the tails. Such distribution is less likely to accurately describe our clast populations that were sampled down to $2 \mathrm{~mm}$ only, thus without fine tails. The Weibull distribution is not appropriated to describe clast fragmentation, and better matches well-sorted sediments (e.g. Sun et al., 2004).

We tested the error associated with varying the distribution functions, by comparing the chi-square factor that includes the cumulative errors from all parameters of functional stereology calculation (e.g. mean, sigma, etc.). Although the chi-square factor is dependent on the "quality" of the sample, the tests done on natural and synthetic populations attest of the good fit between log-normal, logistic and Gamma distributions, in contrary to the Weibull distribution that always has a higher chi-square value (Fig. 7).

Functional stereology cannot be used on images of uneven surfaces. Tests made on images of natural outcrops of unconsolidated pyroclastic deposits are inconsistent with sieving data where the coarsest clasts are standing out of a vertical cliff face (Fig. 8), because the coarse clasts seem to out-number the finer grained clasts. This can be addressed in future studies by developing correction routines for such coarse clasts (so called "projectional stereology").

\subsection{Advantages of the functional stereology technique}

The functional stereology technique has several advantages. This inexpensive method allows fast calculation of statistical values from pre-selected samples on 2D sections. It allows for narrow bin sizes and can therefore be very effective in studies of clastic rocks that are sensitive to variations in grain sizes. Small size increments between bins should be used when multiple modes are suspected (e.g. $1 / 4 \phi$, as used with this technique; Fig. 5).

Calculation of up to three modes is included in the functional stereology code. Calculating the modes of grain size populations was avoided in the early stages of research on the statistical treatment of sieving data, because of the complexity of the task (Folk, 1980); hence values of generic median and standard deviation were preferred (Krumbein, 1936; Murai, 1961; Walker, 1971; Folk, 1980). Grain size distributions are commonly multi-modal (e.g. Folk, 1980) and the mode has been demonstrated to be a more robust parameter than the median (Sahagian and Maus, 1994), because it is less affected by the presence or absence of a few large grains in the population, or limits in resolution of the smallest particles.

Functional stereology overcomes flaws documented in the sieving technique, such as poor reproducibility of the method due to the shape and roughness of the grains (Sahu, 1965; Kennedy et al., 1985; Fernlund, 1998). The disparity in the density of each type of clast needs to be estimated in both the sieving and stereology methods.

The optical methods of functional stereology enable continuation of the distribution to particle sizes that belong to the identified modes. Most pyroclastic deposits are sieved at $1 \phi$ intervals. The precision of the image analysis is arbitrarily set at $1 / 4 \phi$ intervals, which equals that used for detailed sediment grain size analysis (e.g. Evans et al., 2009) because it may reveal subtle features in the grain size distribution such as hidden secondary modes, and is more accurate in the determination of the dominant mode itself (Fig. 5). 

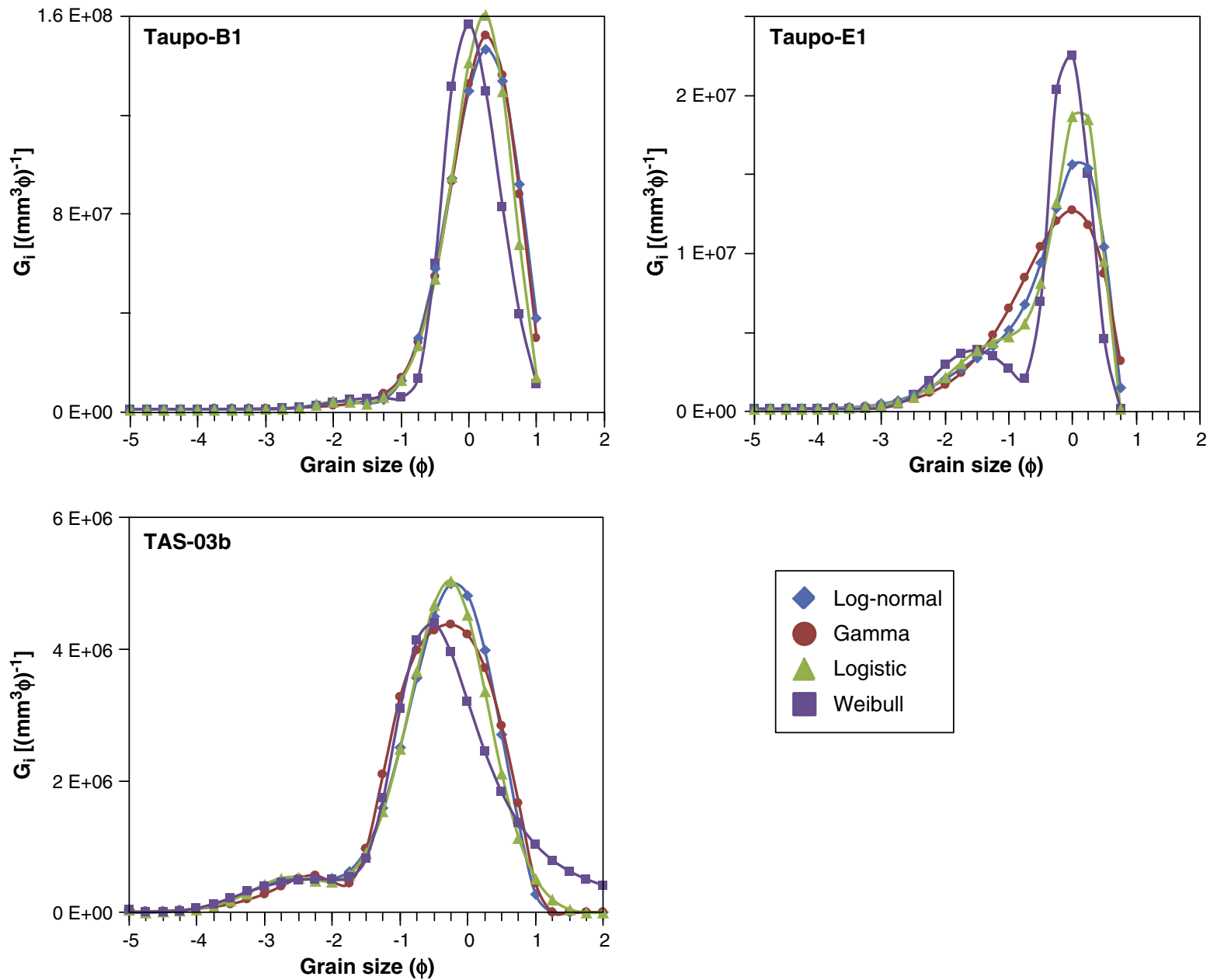

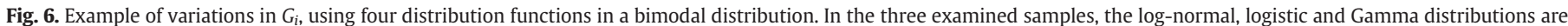
very similar, whereas the Weibull distribution is substantially different. See Fig. 7 for associated errors.

\section{Effects of welding and diagenesis}

This section proposes a method to calculate the former volume of a vesicular pumice clast population that underwent syn- and/or postdeposition compaction by welding and/or diagenesis.

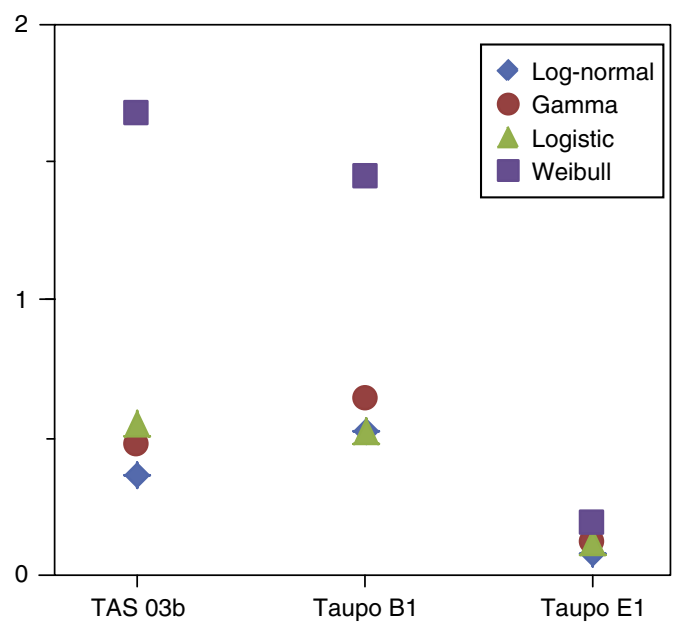

Fig. 7. Chi-square factors on three samples. The Weibull distribution has a consistently higher chi-square factor than the log-normal, logistic and Gamma distributions. See Fig. 6 for the grain size distribution density curves.
An important volcanological application of functional stereology is the study of deposits that were compacted by welding or diagenesis. Welding commonly occurs in pumiceous pyroclastic flow deposits (ignimbrites) and some pyroclastic fall deposits, and produces clastic rocks that are inappropriate for sieving (e.g. Freundt, 1999; Kobberger and Schmincke, 1999; Wilson and Hildreth, 2003; Quane and Russell, 2005; Jutzeler et al., 2010). Diagenesis can affect all clastic aggregates and is responsible for converting them to rocks. Pumice clasts may compact during welding and/or diagenesis, partially or fully losing their initial porosity (Fig. 9a), and becoming fiamme (Bull and McPhie, 2007). Welding and/or diagenetic compaction is here approximated (Fig. 9c) by flattening by pure volume strain (Quane and Russell, 2005). Diameter modification is mostly effective on the axis parallel to the main stress, because the matrix and other clasts surrounding the fiamme also resist the compaction. Here, we do not consider complex deformation (e.g. simple shear and torsion of clasts) that can happen during strong welding and rheomorphism and/or during strong folding. The size of the original pumice clast cannot be precisely reconstructed from its compacted equivalent because, in most cases, the original degree of vesicularity is unknown. The intensity and style of compaction may also vary depending on the former clast size (Bull and McPhie, 2007), and fiamme may not be fully compacted.

The average fiamme diameter in two dimensions is compared with a reconstructed tri-dimensional diameter for various former vesicularities, assuming a regional diagenetic compaction by volume strain (Fig. 9). Functional stereology on the fiamme shifts the two- 

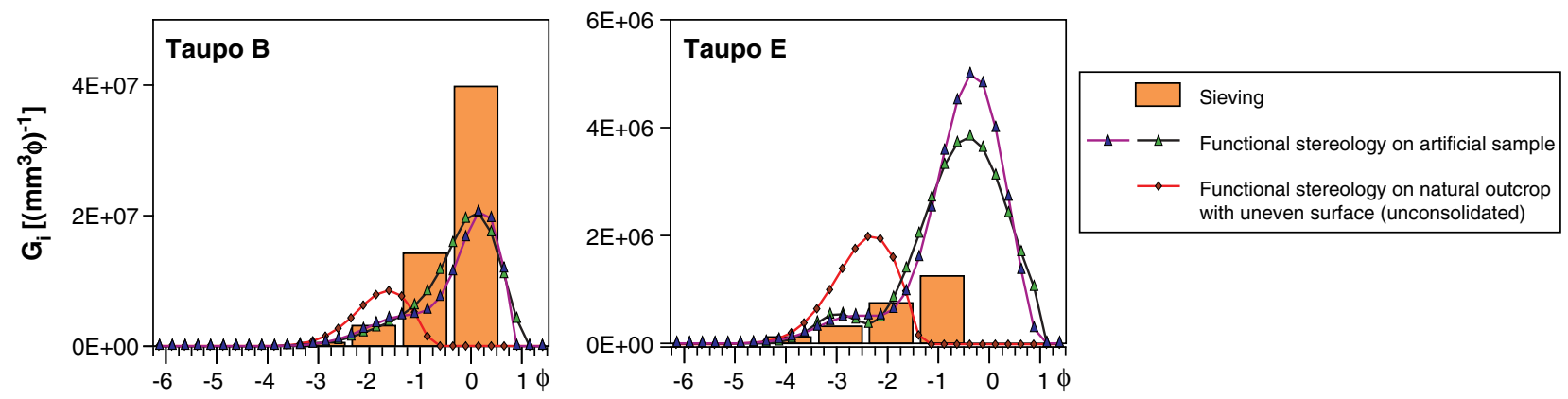

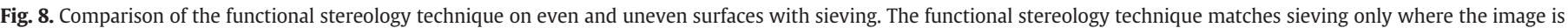

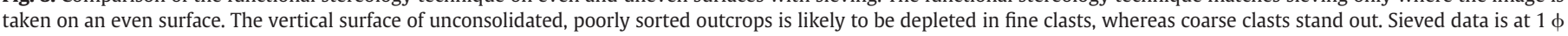

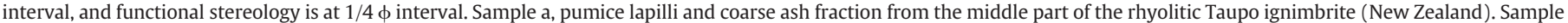
b, breccia and coarse sand fraction of reworked pumice deposit (Taupo Volcanic Zone, New Zealand). See Fig. 4 for key.

dimensional average diameter towards coarser values. The addition of 40,60 and 80 vol.\% of porosity to the fiamme also increases the average diameter values towards coarser values (Fig. 9b). In the studied example, sample B-3 at Cougar Lake, in the Ohanapecosh Formation (Washington State, United States; Fiske, 1963; Jutzeler, 2011) the application of the functional stereology method and fiamme "de-flattening" more than doubles the modal diameter of the two-dimensional fiamme, assuming 80 vol.\% vesicularity was lost by pure volume strain.

a

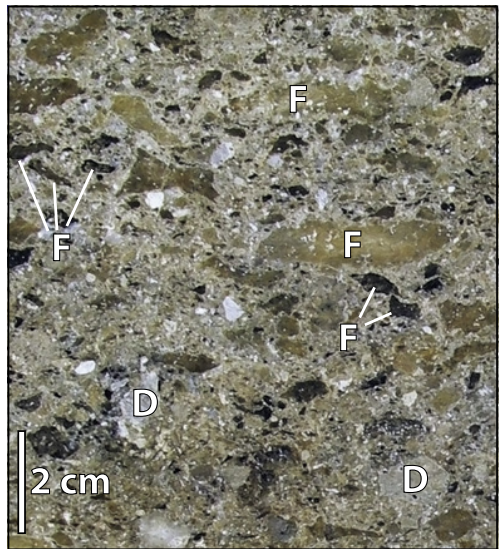

b

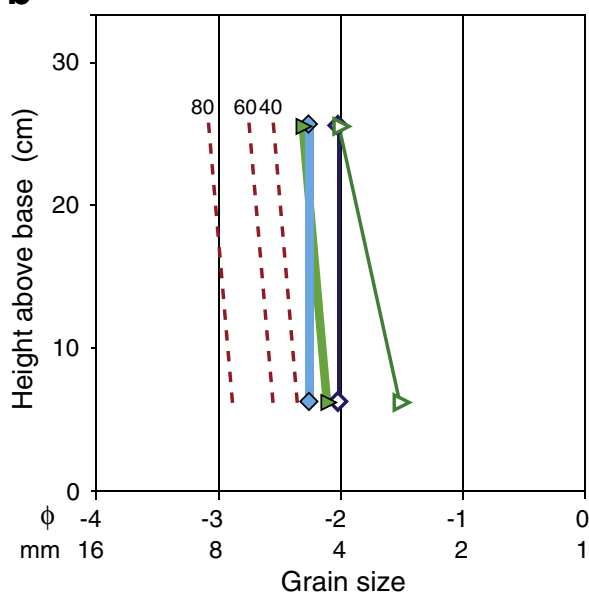

\section{Conclusions}

The application of functional stereology to consolidated pyroclastic rocks enables quantification of the grain size distribution of coarse clast populations, provided that a significant amount of clasts can be separately resolved on a 2D image. The stereological technique described here dramatically increases the number of potential samples because it can be used on consolidated pyroclastic deposits (rocks).
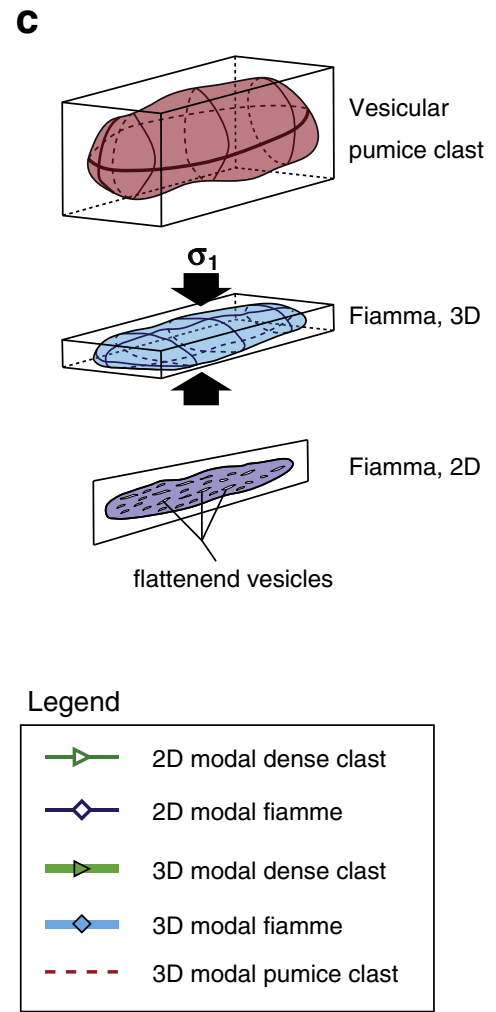

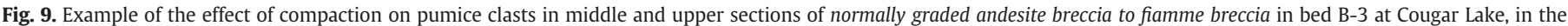

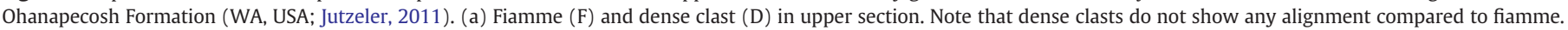

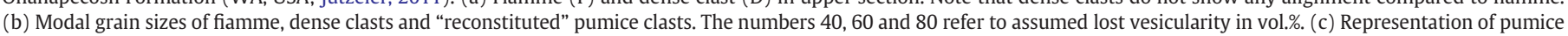
clast compaction to fiamme by pure strain, with principal stress $\sigma_{1}$. 
This should broaden the realm of research on pyroclastic deposits, including clast-forming processes, transport and deposition.

The good match between sieving and stereology results, as well as those undertaken by Proussevitch et al. (2007a), demonstrate the validity of the method for various natural object populations. Because natural clasts have highly variable shape and density, both sieving and stereology give only a statistical estimate of the grain size distribution in a given population. This technique which uses image analysis and functional stereology is more precise than sieving at $1 \phi$ because it can handle data in smaller bins, and thus is more accurate in retrieving the values of the modes. The major limitation of this technique resides in the state of texture preservation of the rock, which excludes fine grain sizes and alteration which masks grain shape $(<0.5-2 \mathrm{~mm})$. Reconstruction of the volume of the former vesicular pumice allows textural characterization of compacted deposits. Two-dimensional fiamme size estimates on a cross-section of a compacted volcaniclastic rock can deviate by more than a factor of 2 from the modal volume of the original pumice clast aggregate. As such, functional stereology should represent a major step forward in our ability to quantify grain size of any clastic aggregate, including volcaniclastic deposits of concern to the volcanic modeling and hazard communities.

\section{Acknowledgments}

The research was funded by ARC-CODES grants to M. Jutzeler and S.R. Allen, and is part of the PhD thesis of M. Jutzeler. A. Proussevitch's contribution was funded by NSF under award AER-0838292. We thank R. Carey for sampling in New Zealand. G. Gualda, J. McPhie, B.F. Houghton and C.J.N. Wilson are acknowledged for careful review and suggestions on the manuscript.

\section{References}

Boggs, S., 2006. Principles of Sedimentology and Stratigraphy. Pearson Prentice Hall, Upper Saddle River. 784 pp.

Bonadonna, C., Houghton, B.F., 2005. Total grain-size distribution and volume of tephrafall deposits. Bulletin of Volcanology 67, 441-456. http://dx.doi.org/10.1007/ s00445-004-0386-2.

Bruning, J.L., Kintz, B.L., 1997. Computational Handbook of Statistics. Longman, New York. $361 \mathrm{pp}$.

Bull, K.F., McPhie, J., 2007. Fiamme textures in volcanic successions: flaming issues of definition and interpretation. Journal of Volcanology and Geothermal Research 164, 205-216. http://dx.doi.org/10.1016/j.jvolgeores.2007.05.005.

Capaccioni, B., Valentini, L., Rocchi, M.B.L., Nappi, G., Sarocchi, D., 1997. Image analysis and circular statistics for shape-fabric analysis: applications to lithified ignimbrites. Bulletin of Volcanology 58, 501-514. http://dx.doi.org/10.1007/s004450050158.

Cas, R.A.F., Wright, J.V., 1987. Volcanic Successions, Modern and Ancient: A Geological Approach to Processes, Products and Successions. Allen \& Unwin, London, United Kingdom (GBR). 528 pp.

Cashman, K.V., 1988. Crystallization of Mount St. Helens 1980-1986 dacite: a quantitative textural approach. Bulletin of Volcanology 50, 194-209. http://dx.doi.org/ 10.1007/BF01079682.

Castro, J.M., Cashman, K.V., Manga, M., 2003. A technique for measuring 3D crystal-size distributions of prismatic microlites in obsidian. American Mineralogist 88, 1230-1240.

Degruyter, W., Bachmann, O., Burgisser, A., 2010. Controls on magma permeability in the volcanic conduit during the climactic phase of the Kos Plateau Tuff eruption (Aegean Arc). Bulletin of Volcanology 72, 1-12. http://dx.doi.org/10.1007/s00445-009-0302-x.

Dufek, J., Bergantz, G.W., 2007. Dynamics and deposits generated by the Kos Plateau Tuff eruption: controls of basal particle loss on pyroclastic flow transport. Geochemistry, Geophysics, Geosystems 8, Q12007. http://dx.doi.org/10.1029/2007GC001741.

Evans, J.R., Huntoon, J.E., Rose, W.I., Varley, N.R., Stevenson, J.A., 2009. Particle sizes of andesitic ash fallout from vertical eruptions and co-pyroclastic flow clouds, Volcán de Colima, Mexico. Geology 37, 935-938. http://dx.doi.org/10.1130/G30208A.1.

Fernlund, J.M.R., 1998. The effect of particle form on sieve analysis: a test by image analysis. Engineering Geology (Amsterdam, Netherland) 50, 111-124. http:// dx.doi.org/10.1016/S0013-7952(98)00004-0.

Fiske, R.S., 1963. Subaqueous pyroclastic flows in the Ohanapecosh Formation, Washington. Geological Society of America Bulletin 74, 391-406. http://dx.doi.org/10.1130/00167606(1963) 74[391:SPFITO]2.0.CO;2.

Folk, R.L., 1980. Petrology of Sedimentary Rocks. Hemphill Publ. Co., Austin. 184 pp.

Freundt, A., 1999. The formation of high-grade ignimbrites, Part II. A pyroclastic suspension current model with implications also for low-grade ignimbrites. Bulletin of Volcanology 60, 545-567. http://dx.doi.org/10.1007/s004450050251.
Gonzalez, R.C., Woods, R.E., 2008. Digital Image Processing Using MATLAB: AND "Mathworks, MATLAB Sim SV 07". Prentice Hall Press, Upper Saddle River, N.J.

Gualda, G.A.R., Baker, M., 2006. Quantitative 3D petrography using X-ray tomography: application to Bishop Tuff pumice clasts. Journal of Volcanology and Geothermal Research 154, 48-62. http://dx.doi.org/10.1016/j.jvolgeores.2005.09.019.

Gualda, G.A.R., Baker, D.R., Polacci, M., 2010. Introduction: advances in 3D imaging and analysis of geomaterials. Geosphere 6, 468-469. http://dx.doi.org/10.1130/GES00639.1.

Higgins, M.D., 2000. Measurement of crystal size distributions. American Mineralogist 85, 1105-1116.

Jerram, D.A., Davidson, J.P., 2007. Frontiers in textural and microgeochemical analysis. Elements 3, 235-238. http://dx.doi.org/10.2113/gselements.3.4.235.

Jerram, D.A., Davis, G.R., Mock, A., Charrier, A., Marsh, B.D., 2010. Quantifying 3D crystal populations, packing and layering in shallow intrusions: a case study from the Basement Sill, Dry Valleys, Antarctica. Geosphere 6, 537-548. http://dx.doi.org/ 10.1130/GES00538.1.

Jutzeler, M., 2011. Characteristics and origin of subaqueous pumice-rich pyroclastic facies: Ohanapecosh Formation (USA) and Dogashima Formation (Japan). Ph.D. Thesis, University of Tasmania, Hobart, Australia, 205 pp.

Jutzeler, M., Schmincke, H.U., Sumita, M., 2010. The incrementally zoned Miocene Ayagaures ignimbrite (Gran Canaria, Canary Islands). Journal of Volcanology and Geothermal Research 196, 1-19. http://dx.doi.org/10.1016/j.jvolgeores.2010.07.002.

Karatson, D. Sztano, O., Telbisz, T, 2002. Preferred clast orientation in volcaniclastic mass-flow deposits: application of a new photo-statistical method. Journal of Sedimentary Research 72, 823-835. http://dx.doi.org/10.1306/040402720823.

Kellerhals, R., Shaw, J., Arora, V.K., 1975. On grain size from thin sections. Journal of Geology 83, 79-96.

Kennedy, S.K., Meloy, T.P., Durney, T.E., 1985. Sieve data - size and shape information. Journal of Sedimentary Petrology 55, 356-360.

Kervyn, M., et al., 2010. 3D imaging of volcano gravitational deformation by computerized X-ray micro-tomography. Geosphere 6, 482-498. http://dx.doi.org/10.1130/ GES00564.1

Ketcham, R.A., Slottke, D.T., Sharp Jr., J.M., 2010. Three-dimensional measurement of fractures in heterogeneous materials using high-resolution X-ray computed tomography. Geosphere 6, 499-514. http://dx.doi.org/10.1130/GES00552.1.

Kobberger, G., Schmincke, H.U., 1999. Deposition of rheomorphic ignimbrite D (Mogán Formation), Gran Canaria, Canary Islands, Spain. Bulletin of Volcanology 60, 465-485. http://dx.doi.org/10.1007/s004450050246.

Krumbein, W.C., 1936. Application of logarithmic moments to size-frequency distributions of sediments. Journal of Sedimentary Petrology 6, 35-47.

Macedonio, G., Costa, A., Folch, A., 2008. Ash fallout scenarios at Vesuvius: numerical simulations and implications for hazard assessment. Journal of Volcanology and Geothermal Research 178, 366-377. http://dx.doi.org/10.1016/j.jvolgeores.2008.08.014.

McPhie, J., Doyle, M., Allen, R., 1993. Volcanic Textures. ARC-Centre of Excellence in Ore Deposits University of Tasmania. $198 \mathrm{pp}$.

Mock, A., Jerram, D.A., 2005. Crystal size distributions (CSD) in three dimensions: insights from the 3D reconstruction of a highly porphyritic rhyolite. Journal of Petrology 46, 1525-1541. http://dx.doi.org/10.1093/petrology/egi024.

Murai, I., 1961. A study of the textural characteristics of pyroclastic flow deposits in Japan. Bulletin of the Earthquake Research Institute 39, 133-248.

Polyanin, A.D., Manzhirov, A.V., 2008. Handbook of integral equations. Handbooks of Mathematical Equations. Chapman \& Hall/CRC, Boca Raton, FL, p. 1108.

Press, W.H., Teukolsky, S.A., Vetterling, W.T., Flannery, B.P., 1992. Numerical Recipes in C. Cambridge University Press, Cambridge, U.K.

Proussevitch, A.A., Sahagian, D.L., 2001. Recognition and separation of discrete objects within complex 3D voxelized structures. Computers \& Geosciences 27, 441-454 http://dx.doi.org/10.1016/S0098-3004(00)00141-2.

Proussevitch, A.A., Sahagian, D.L., Carlson, W.D., 2007a. Statistical analysis of bubble and crystal size distributions: application to Colorado Plateau basalts. Journal of Volcanology and Geothermal Research 164, 112-126. http://dx.doi.org/10.1016/ j.jvolgeores.2007.04.006.

Proussevitch, A.A., Sahagian, D.L., Tsentalovich, E.P., 2007b. Statistical analysis of bubble and crystal size distributions: formulations and procedures. Journal of Volcanology and Geothermal Research 164, 95-111. http://dx.doi.org/10.1016/j.jvolgeores 2007.04.007.

Quane, S.L., Russell, J.K., 2005. Ranking welding intensity in pyroclastic deposits. Bulletin of Volcanology 67, 129-143. http://dx.doi.org/10.1007/s00445-004-0367-5.

Sahagian, D.L., Maus, J.E., 1994. Basalt vesicularity as a measure of atmospheric pressure and palaeoelevation. Nature 372,449-451. http://dx.doi.org/10.1038/372449a0.

Sahagian, D.L., Proussevitch, A.A., 1998. 3D particle size distributions from 2D observations: stereology for natural applications. Journal of Volcanology and Geothermal Research 84, 173-196. http://dx.doi.org/10.1016/S0377-0273(98)00043-2.

Sahu, B.K., 1965. Theory of sieving. Journal of Sedimentary Petrology 35, 750-753.

Schmincke, H.-U., 2004. Volcanism. Springer-Verlag. 324 pp.

Shea, T., et al., 2010. Textural studies of vesicles in volcanic rocks: an integrated methodology. Journal of Volcanology and Geothermal Research 190, 271-289. http:/ dx.doi.org/10.1016/j.jvolgeores.2009.12.003.

Sun, D., et al., 2004. Bimodal grain-size distribution of Chinese loess, and its palaeoclimatic implications. Catena 55, 325-340. http://dx.doi.org/10.1016/s03418162(03)00109-7.

Van Den Berg, E.H., Meesters, A.G.C.A., Kenter, J.A.M., Schlager, W., 2002. Automated separation of touching grains in digital images of thin sections. Computers \& Geosciences 28, 179-190. http://dx.doi.org/10.1016/S0098-3004(01)00038-3.

Volentik, A.C.M., Bonadonna, C., Connor, C.B., Connor, L.J., Rosi, M., 2010. Modeling tephra dispersal in absence of wind: insights from the climactic phase of the $2450 \mathrm{BP}$ Plinian eruption of Pululagua volcano (Ecuador). Journal of Volcanology and Geothermal Research 193, 117-136. http://dx.doi.org/10.1016/j.jvolgeores.2010.03.011. 
Walker, G.P.L., 1971. Grain-size characteristics of pyroclastic deposits. Journal of Geology 79, 696-714.

Walker, G.P.L., 1973. Explosive volcanic eruptions - a new classification scheme Geologische Rundschau 62, 431-446. http://dx.doi.org/10.1007/BF01840108.

Walton, W.H., 1948. Feret's statistical diameter as a measure of particle size. Nature 162, 329-330. http://dx.doi.org/10.1038/162329b0.

Wentworth, C.K., 1922. A scale of grade and class terms for clastic sediments. Journal of Geology 30, 377-392.
Wilson, C.J.N., Hildreth, W., 2003. Assembling an ignimbrite: mechanical and thermal building blocks in the Bishop Tuff, California. Journal of Geology 111, 653-670. http://dx.doi.org/10.1086/378335.

Wohletz, K.H., Sheridan, M.F., Brown, W.K., 1989. Particle size distributions and the sequential fragmentation/transport theory applied to volcanic ash. Journal of Geophysical Research 94, 15703-15721. http://dx.doi.org/10.1029/JB094iB11p15703. 